EPJ Web of Conferences 45, 01087 (2013)

DOI: $10.1051 /$ epjconf/20134501087

(C) Owned by the authors, published by EDP Sciences, 2013

\title{
Prismatic Blade Measuring on a Wind Tunnel
}

\author{
P. Epikaridis ${ }^{1, \mathrm{a}}$, K. Sedlak ${ }^{\mathrm{b}}$ and J. Stech ${ }^{2, \mathrm{c}}$ \\ ${ }^{1}$ Experimental Research, R\&D department, SKODA POWER, Tylova 1/57, 30128 Pilsen, CZ \\ ${ }^{2}$ Department of Power System Engineering, University of West Bohemia, Univerzitni 22, 30614 Pilsen, CZ
}

\begin{abstract}
The results from measurement on the straight blade cascade are presented in the paper. The cascade is placed at the outlet of wind tunnel in ŠKODA POWER experimental base. The results in the form of velocity and loss fields behind blade cascade as well as the distribution of the loss coefficient in selected cross-section are evaluated.
\end{abstract}

\section{Introduction}

After a l ong break was re-commissioned wind tunnel, which is designed to direct research blade cascade. In the initial stage, it was necessary to identify a suitable blade cascade, which could be used as a $r$ eference for subsequent measurements. The selected stator prismatic blades were created from VS33 profile. An important factor in this decision was the fact that there is sufficient database data, which can be covered by the new results and verify them.

Although the direct measurement of blade cascades fully reflect reality, which is significantly more complicated and can be better understood perhaps only on air turbines, it is important to realize that even this evolutionary phase blade profiles makes sense. The blade cascade measurement is cheaper and faster. Moreover, it is possible to study processes happening inside the blade channels. In air turbines is it very difficult to do that. Also for this reason it is appropriate to apply the results already known blade cascade.

The tunnel is open, measurement space is located at the output of the adjustable convergent nozzle. Blade cascade is made with four blades. It is mounted on the extended outlet nozzle.

Aerodynamic parameters of the tunnel (Mach and Reynolds number) are below then the parameters on real turbines, the blade models are adapted. Length of blade is adjustable in the range from 150 to $300 \mathrm{~mm}$, blade chord length $b=200 \mathrm{~mm}$. Operating Reynolds number of blade is $7.5 \mathrm{e} 5$, Mach isentropic number is 0.2 . In the presented case, the length of the blade was $150 \mathrm{~mm}$ in the relative spacing $\mathrm{t} / \mathrm{b}=0.7$.

The tunnel allows to measure selected characteristics of the blade cascade in a wide range of angle of attack of the blade cascade flow. Another big advantage is the ability to identify flow characteristics at different distances behind the trailing edge of the blades, but also inside of blade channel. In addition, it is possible to study the secondary flow arising at restricting walls. It is these areas significantly affect the efficiency, respectively losses all blade channel.

\section{Secondary flowing}

Secondary flowing is three-dimensional flowing which is in end walls of a blade channel. Due to fluid flows through the blade channel occurs across the channel pressure gradient. This pressure distribution in the channel is distributing of pressure on a blade profile and the force formation strength.

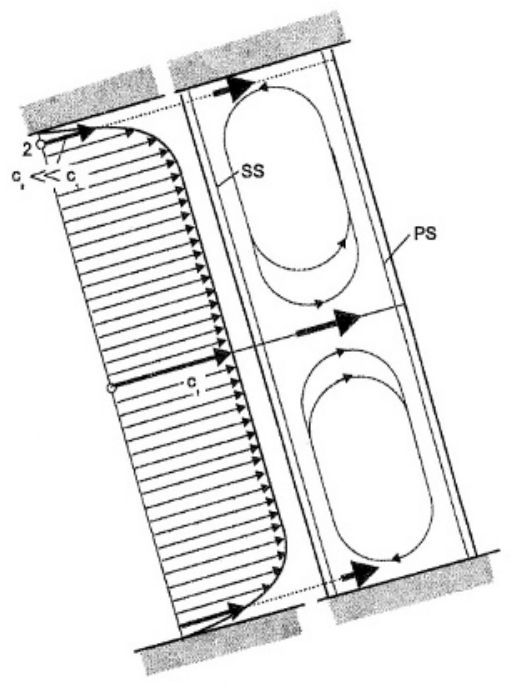

Fig. 1. Secondary losses origin 
Result of different pressure gradient along the height of blade channel is formed by the secondary flow. Near the endwall surfaces is fluid velocity less than in the middle of the channel, there is a much smaller pressure gradient. Therefore, in the channel end wall goes a flowing from pressure side (PS) to the suction side of the blade (SS). Passage vortexes originate, figure 1.

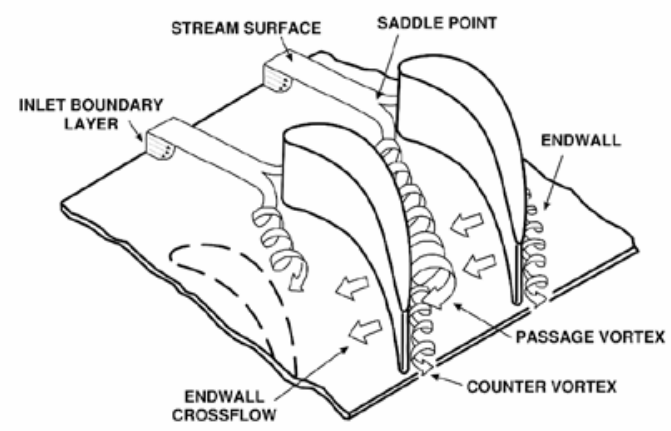

Fig. 2. Flowing in a blade channel

This vortexes couple make the secondary flowing in the blade channel. This flowing makes a flow across blade channel (figure 2) and flow along blade high. At the pressure side fluid goes from a middle of blade to endwalls and at the suction side fluid goes from the endwalls to the middle of a blade.

The passage vortex and counter vortex arise in front of a blade. Vortex from pressure profile side goes during endwall crossflow to suction side of blade channel. The passage vortex moves counter vortex along the blade to the middle of a channel.

Secondary losses occur mainly in the peripheral parts of the channel endwall. For short blades used in high pressure stages may exceed the loss profile. Therefore, it is necessary to reduce secondary losses to a minimum.

\section{Measurement description}

Use flow characteristics measurement of blade cascade was created on the wind tunnel in the laboratories of ŠKODA POWER, figure 3. Parameters described are secured tunnel axial fan JU 60. Fan control can be solved by setting vanes, respectively with bypass, which is located behind the fan. Fan achieves compression is $4400 \mathrm{~Pa}$, mass flow rate is $20 \mathrm{~m}^{3} \mathrm{~s}^{-1}$ [1].

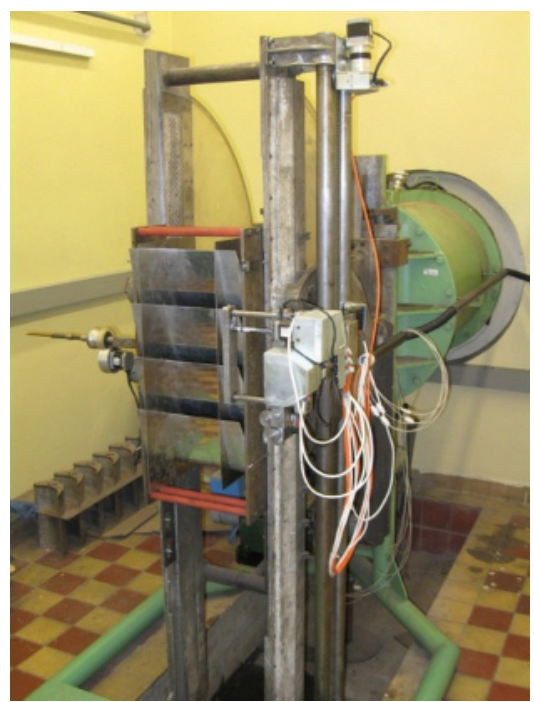

Fig. 3. Wind tunnel

Flow characteristics measurement of blade cascade is based on the conventional method of collecting data from pneumatic probes located before and after the measured blade cascade, figure 4 .



Fig. 4. Scanning pressure differences schema

The fixed Prandtl probe is in the plane 0, which is plane behind convergent nozzle. From the data obtained in this section are evaluated parameters set wind tunnel [2].

Pitot probe is located in plane 1 , which movement is related with the 5-hole probe. It is traversing the output field in the plane 2, which is a plane behind blade cascade. This pair of probes is complemented by taking static pressure on the wall also in the plane 1. For further evaluation of loss factors are fundamental data was obtained from the pair of probes.

To measure was used intelligent pressure transmitter NetScanner 9116, which communicates with the measuring computer via an Ethernet network using TCP/IP.

Flow temperature, atmospheric pressure and humidity were also evaluated. 


\section{Results}

The first evaluated magnitude was velocity distribution in the plane 2, figure 5. Everything is displayed in a standardized coordinate system $\mathrm{r} / \mathrm{l}-\mathrm{u} / \mathrm{t}$, the value 0 on the vertical axis corresponds to the pressure side blade, while a value of 1 corresponds to the suction blade side. The values 0 and 1 on the horizontal axis correspond to the walls of the tunnel. The graph in figure 4 , is cut of surface in figure 3 in the centre of the channel, in direction $\mathrm{z} / \mathrm{b}=0.1$ behind the blade trailing edge.

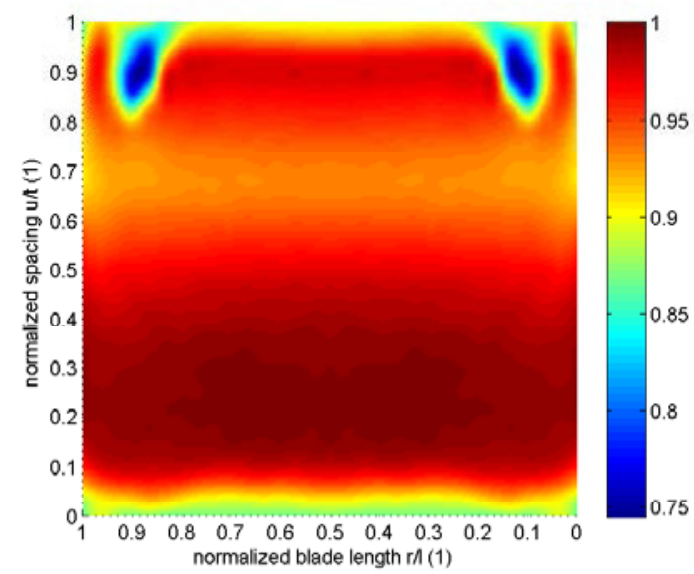

Fig. 5. Speed module (distance $\mathrm{z} / \mathrm{b}=0.1$ behind the blade trailing edge)

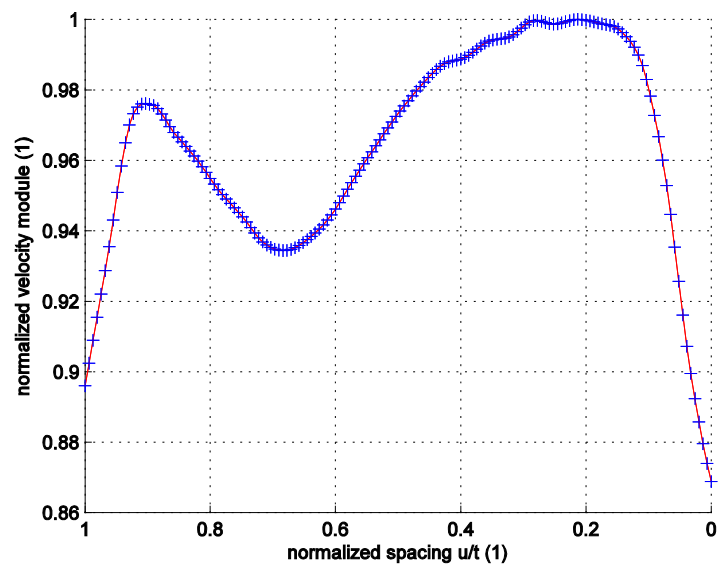

Fig. 6. Speed module in the middle of a blade channel (distance $\mathrm{z} / \mathrm{b}=0.1$ behind the blade trailing edge)

Graph in figure 5 shows vortexes in area at hub and tip o blade. They extend about a quarter of the length of the channel. From this we can say, that in the interval $\mathrm{r} / \mathrm{l}=$ 0.25 to 0.75 of blade length, the flow isn't affected by the secondary losses. There is a decline in the rate on the suction blade side, which could be due to the presence of separation bubble on the pressure side or a big boundary layer thickness.

The following figures (figure 7, figure 8) show the distribution of normalized loss coefficient in the same coordinate system.

The maximum values of loss coefficient have in hub and tip of the blade, figure 7. This is due to counter vortex, which arises in the corners about half of the length of the channel and it goes through the whole channel from the pressure side to the suction side of blade. For a better idea is the scalar field added yet classic two-dimensional graph, figure 8 , which describes the distribution loss factor in $\mathrm{r} / \mathrm{l}=0.16$. This is an area where the dominant role has mentioned vortexes. It is evident that the local loss coefficient is about $70 \%$ higher than the loss coefficient in the middle of the blade channel.

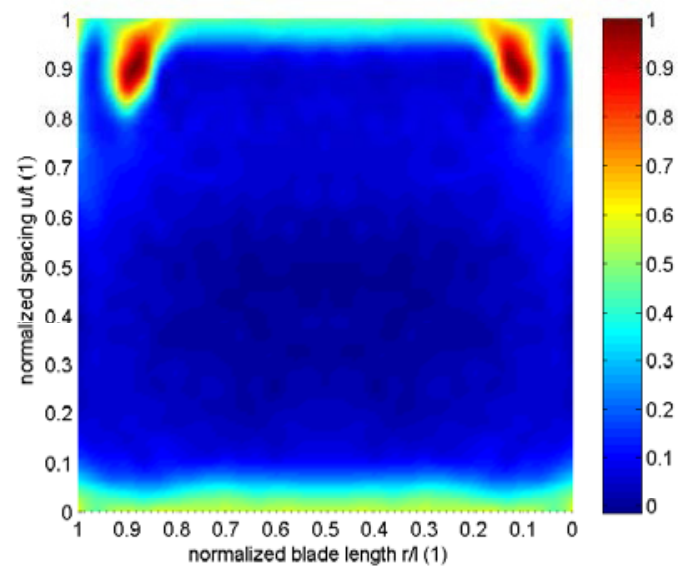

Fig. 7. Scalar field of loss coefficient (distance $\mathrm{z} / \mathrm{b}=0.1$ behind the blade trailing edge)

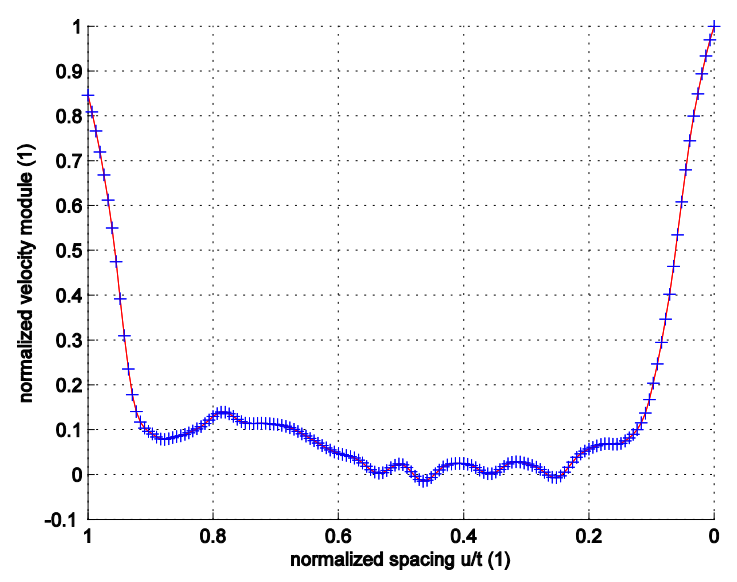

Fig. 8. Losses across spacing in vortex area

The graph in the figure 9 shows the effect of distance behind the trailing edge of the blades to the size of loos coefficient. It appears that an inappropriate choice of the measuring plane may increase the value of the loss coefficient up to $10 \%$ relative. In this time we use the results from the measuring at distance $\mathrm{z} / \mathrm{b}=0.1$, but in future it will be necessary to change this value and to introduce a correction for axial distance degrees.

The last picture (figure 10) shows losses distribution in different distance behind trailing edge of the blade. 


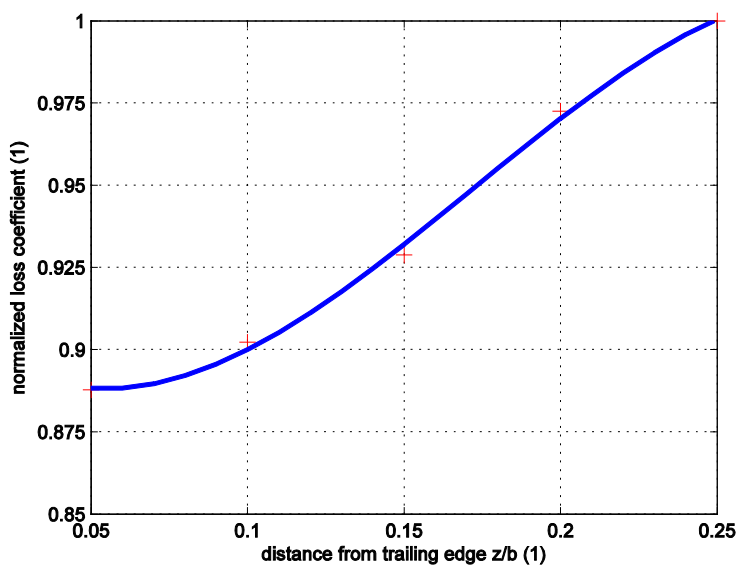

Fig. 9. Losses evolution in axial direction behind blades

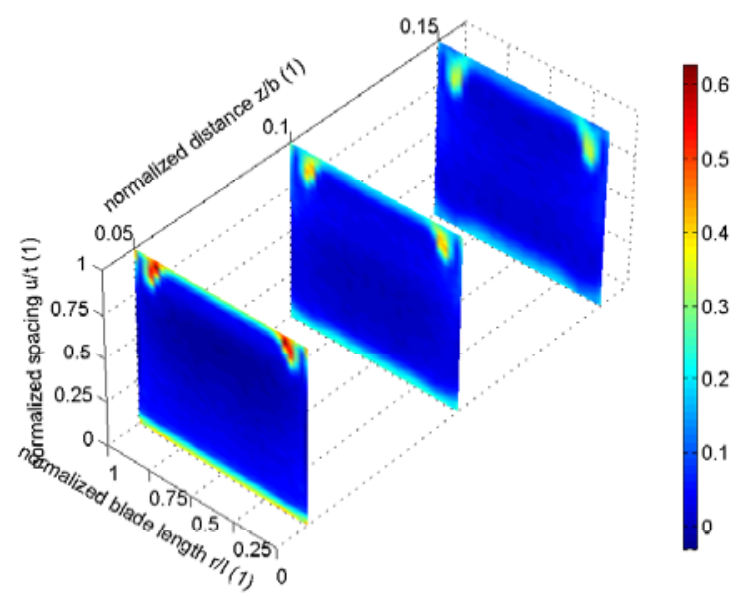

Fig. 10. Losses evolution behind trailing blade edge

\section{Conclusion}

The report presents the results of measurements prismatic blade cascade with profile VS33. Series of measurements was performed at several distances behind the trailing edge of the blade channel. The result is a s calar and vector field velocity, loss coefficient depending on the distance from the trailing edge of the blades. The next step will be to extend the measured areas, investigating the impact of axial distance for losses and transition to a $3 \mathrm{D}$ curved blades.

\section{Acknowledgement}

Presented research works have been supported by the grant project MPO FR-TI3/432 „Komplexní vývoj přetlakového stupně s vysokou účinností”.

\section{References}

1. J. Peprný, K. Pekárek Výstavba středorychlostního aerodynamického tunelu na lopatkové mř́že (Výzkumná zpráva Škoda, 1965)
2. J. Brich, M. Št'astný Postup zpracování experimentálnich dat výzkumu třirozmérného prouděni nestlačitelné tekutiny rovinnou lopatkovou mř́ži turbínového typu a program AA5B (Výzkumná zpráva Škoda VVZ, 1977)

3. A. Klein, BHRA T 1004 (1966)

4. L.S. Langston, M.L. Nice, R.M. Hooper, ASME, 99 (1977) 